\title{
Phylogenetic Analysis and Fungicide Baseline Sensitivities of Monilia mumecola in China
}

\author{
L. F. Yin, ${ }^{1}$ S. F. Du, ${ }^{2}$ C. Chaisiri, ${ }^{2}$ R. Cheewangkoon, ${ }^{3}$ and C. X. Luo ${ }^{4, \dagger}$ \\ ${ }^{1}$ Key Lab of Horticultural Plant Biology, Ministry of Education, and Experimental Teaching Center of Crop Science, Huazhong \\ Agricultural University, Wuhan 430070, China \\ ${ }^{2}$ College of Plant Science and Technology and the Key Lab of Crop Disease Monitoring \& Safety Control in Hubei Province, \\ Huazhong Agricultural University, Wuhan 430070, China \\ ${ }^{3}$ Department of Entomology and Plant Pathology, Faculty of Agriculture, Chiang Mai University, Chiang Mai 50200, Thailand \\ ${ }^{4}$ Key Lab of Horticultural Plant Biology, Ministry of Education, and College of Plant Science and Technology, Huazhong \\ Agricultural University, Wuhan 430070, China
}

\begin{abstract}
Monilia mumecola is one of the causal agents of peach brown rot in China. In this study, M. mumecola isolates from different locations and hosts were used to analyze the genetic diversity and to assay the sensitivity to four generally used fungicides: carbendazim, tebuconazole, azoxystrobin, and boscalid. Results showed that isolates from different locations tended to be separated. Interestingly, isolates from different hosts (e.g., peach and apricot) at the same locations generally clustered

mycelial growth inhibition values for carbendazim, tebuconazole, azoxystrobin, and boscalid were $0.103,0.034,0.325$, and $0.419 \mu \mathrm{g} / \mathrm{ml}$, respectively. The sensitivity distributions of the tested isolates to the four fungicides showed continuous unimodal curves, indicating no qualitative shift of resistance. No significant difference of sensitivity to tested fungicides was observed among isolates from either different locations or different hosts.
\end{abstract} together, indicating that the $M$. mumecola isolates may infect different hosts in the same areas. The fungicide sensitivity assay of $93 \mathrm{M}$. mumecola isolates showed that the average effective concentration for $50 \%$
Keywords: baseline sensitivity, brown rot, fungicides, genetic diversity, Monilia mumecola
China is the origin of peach trees and the leading producer of peach fruit (Prunus persica L. Batsch) in the world. According to the United States Department of Agriculture, the world peach and nectarine production in 2016-17 was about 20 million tons, of which 13.5 million tons came from China, accounting for $67.5 \%$ of the global production. Many diseases pose a threat to peach quality and production in China; among them is brown rot disease. Recent studies revealed that Monilinia fructicola, Monilia mumecola, and Monilia yunnanensis are the main causal agents of peach brown rot in China (Hu et al. 2011a; Luo 2017; Yin et al. 2015). These species also cause brown rot on other stone fruit, including nectarine, plum, apricot, and cherry (Luo 2017).

M. mumecola was first isolated in Japan from mume ( $P$. mume), which was initially thought to be $M$. laxa, because both species shared similar colony appearance and generally cause blossom and shoot blight (Harada et al. 1990). In 2004, it was identified as a new species (Harada et al. 2004). Since then, M. mumecola was reported as the causal agent of brown rot on Chinese quince (Pseudocydonia sinensis) (Shao 2009), peach (Hu et al. 2011a), apricot, cherry, and plum (Luo 2017; Yin et al. 2014a,b, 2015) in China.

Fungicide applications have been the most effective method for preharvest and postharvest control of brown rot worldwide. Chinese growers also frequently use fungicides such as methyl benzimidazole carbamates (MBCs), demethylation inhibitors (DMIs), quinone

\section{Corresponding author: C. X. Luo; cxluo@mail.hzau.edu.cn}

Funding: This work was financially supported by the earmarked fund for Peach Modern Agro-industry Technology Research System (CARS-30), and by The Projects of National Natural Science Foundation of China (31401686 and 31872934).

The author(s) declare no conflict of interest.

Accepted for publication 9 March 2019.

(c) 2019 The American Phytopathological Society outside inhibitors (QoIs), and succinate dehydrogenase inhibitors (SDHIs) to prevent losses to rot.

These fungicides act primarily on the biochemical pathway and, thus, are prone to the development of resistance. Fungicide resistance has been reported in three Monilinia spp. worldwide. M. fructicola has developed resistance to MBCs, DMIs, and SDHIs, and reduced sensitivity to QoIs. Resistance to MBCs was first reported as early as in 1976 (Szkolnik and Gilpatrick 1977), then reported worldwide (Chen et al. 2014; Egüen et al. 2016; Fan et al. 2009; Fang et al. 2010; Ma et al. 2003; May-De Mio et al. 2011; Michailides et al. 1987). DMI fungicide resistance was first reported in the 1980s, and then in New Zealand (Elmer et al. 1992), Brazil (May-De Mio et al. 2011), the United States (Burnett et al. 2010; Chen et al. 2013b; Luo et al. 2008; Schnabel et al. 2004), and Spain (Egüen et al. 2016). Although boscalid-resistant field isolates have been reported, no mutations in the subunits $\mathrm{SdhA}, \mathrm{SdhB}, \mathrm{SdhC}$, and $\mathrm{SdhD}$ of the succinate dehydrogenase were observed in boscalid-resistant isolates of $M$. fructicola (Amiri et al. 2010; Chen et al. 2013a). As for QoIs, studies showed that isolates can adapt to be reduced sensitivity to azoxystrobin (Amiri et al. 2010; May-De Mio et al. 2011; Villani and Cox 2008).

Fungicide resistance in Monilia laxa and M. fructigena has not been widely reported, likely because these two species are not as widely distributed worldwide compared with $M$. fructicola. Resistance to MBCs in M. laxa was reported in California (Ma et al. 2005), Greece (Malandrakis et al. 2012; Thomidis et al. 2009), and Spain (Egüen et al. 2016). Baseline isolates of M. laxa are more sensitive to DMI and QoI fungicides compared with $M$. fructicola (Spiegel and Stammler 2006), even when isolates derived from the same peach tree (K. Cox, personal communication). Up to now, only laboratory mutants resistant to sterol biosynthesis inhibitor fenhexamid were obtained for $M$. laxa through UV mutagenesis, and all fenhexamid-resistant mutants showed parental sensitivity to MBC, DMI, and QoI fungicides (Malandrakis et al. 2013). No field isolates with reduced sensitivity to SDHIs have been found thus far in M. laxa and M. fructigena. Spiegel and Stammler (2006) found that, although the spores of these two species were able to germinate on medium 
amended with the highest concentration of SDHI fungicide, the mycelial growth was completely inhibited. Similarly, no fungicide resistances were detected in other brown rot pathogens M. polystroma, M. mumecola, and M. yunnanensis.

Although extensive fungicide resistance studies have been carried out in M. fructicola, M. laxa, and M. fructigena, few studies were carried out in M. polystroma, M. yunnanensis, and M. mumecola. With the increasing usage of single-site fungicides in China, it is necessary to establish baseline sensitivities of these species to different fungicides. In order to clarify whether the fungicide sensitivity profiles were affected by genetic diversity of isolates from different locations or hosts, we elucidated their genetic diversity. The objectives of this study were to assess the genetic diversity among M. mumecola isolates from different locations and hosts, and to determine the baseline sensitivity of $M$. mumecola isolates to carbendazim, tebuconazole, azoxystrobin, and boscalid.

\section{Materials and Methods}

Collection of M. mumecola isolates. In total, $93 \mathrm{M}$. mumecola single-spore isolates were obtained from Chongqing municipality and three locations of Hubei Province during 2010 to 2013 (Table 1). Isolates from Wuhan and Ezhou, Hubei Province, were from experimental stations without fungicide application history, and isolates from Chongqing municipality and Xiangfan, Hubei Province were from small family based orchards where carbendazim was occasionally applied. All isolates were identified to species level, as described previously (Hu et al. 2011a).

DNA extraction. Single agar plugs grown on potato dextrose agar (PDA; $200 \mathrm{~g}$ of potato, $20 \mathrm{~g}$ of dextrose, and $15 \mathrm{~g}$ agar per liter) for 5 days at $22^{\circ} \mathrm{C}$ were transferred to potato dextrose broth $(200 \mathrm{~g}$ of potato and $20 \mathrm{~g}$ of dextrose per liter) and incubated for 4 days. Genomic DNA was extracted from harvested mycelia using the Easypure Plant Genomic DNA Extraction Kit (TransGen Biotech). The DNA product was dissolved in $30 \mu \mathrm{l}$ of deionized water and stored at $-20^{\circ} \mathrm{C}$.

Phylogenetic analysis of $\mathrm{M}$. mumecola isolates. Genetic diversity of $91 \mathrm{M}$. mumecola isolates ( 2 isolates were not used because some fragments were not successfully obtained) was analyzed by constructing phylogenetic trees based on six fragments from five genes: sterol 14 $\alpha$-demethylase gene (CYP51), $\beta$-tubulin (TUB2) gene, elongation factor $1 \alpha$ gene $(E F-1 \alpha)$, glyceraldehydes-3-phosphate dehydrogenase gene $(G 3 P D H)$, and cytochrome b gene fragments (Cytb 1 and $C y t b 2$ ). Primers used to amplify corresponding fragments are shown in Table 2.

Polymerase chain reaction (PCR) amplifications were performed with $50-\mu$ l volumes containing $1 \times$ PCR buffer, $50 \mathrm{ng}$ of DNA, $0.4 \mu \mathrm{M}$ each primer, $100 \mu \mathrm{M}$ each dNTP, and $1 \mathrm{U}$ of Easy Taq DNA polymerase (TransGen Biotech Co.) in an iCycler thermal cycler (Bio-Rad Laboratories Inc.). The PCR program was run with the following parameters: an initial preheating at $94^{\circ} \mathrm{C}$ for $4 \mathrm{~min}$; followed by 33 cycles of denaturation at $94^{\circ} \mathrm{C}$ for $1 \mathrm{~min}$, annealing at $55^{\circ} \mathrm{C}$ for $1 \mathrm{~min}$, and extension at $72^{\circ} \mathrm{C}$ for $1 \mathrm{~min}$; with a final extension at $72^{\circ} \mathrm{C}$ for $10 \mathrm{~min}$. PCR products were sequenced at Wuhan Yihui Company.

Table 1. Monilia mumecola isolates used in this study

\begin{tabular}{|c|c|c|c|c|}
\hline Collection sites & Isolate code & $\begin{array}{c}\text { Number } \\
\text { of } \\
\text { isolates }\end{array}$ & Host & $\begin{array}{c}\text { Collection } \\
\text { year }\end{array}$ \\
\hline \multirow[t]{3}{*}{ Chongqing } & $\mathrm{CBN}-7$ & 1 & Cherry & 2013 \\
\hline & CJL-11-1 & 1 & Plum & 2013 \\
\hline & CH-14-1 & 1 & Plum & 2013 \\
\hline Xiangfan, Hubei & HXL10-1a to $6 \mathrm{a}$ & 5 & Peach & 2010 \\
\hline Ezhou, Hubei & MHH1-2a to 9-1a & 11 & Peach & 2013 \\
\hline Wuhan, Hubei & MHT1-3b to $2-2 b$ & 7 & Apricot & 2013 \\
\hline \multirow[t]{2}{*}{ Wuhan, Hubei } & HN12-1a to $13-3 a$ & 26 & Peach & 2013 \\
\hline & HWL10-1a to $26 \mathrm{~b}$ & 41 & $\begin{array}{l}\text { Peach, } \\
\text { nectarine }\end{array}$ & 2010 \\
\hline
\end{tabular}

Before the phylogenetic analysis, partition homogeneity (PTH) was performed to check whether different gene sequences could be combined for phylogenetic analysis. The PTH test (1,000 random partitions) was calculated using PAUP* 4.0 (Swofford 2003) and has been used to test the significance of character congruence. A partition of all fragments (G3PDH, CYP51,TUB2, EF-1 $\alpha, C y t b 1$, and $C y t b 2$ ) was made for 91 isolates for which sequences were available. Tests were performed under parsimony criteria. $M$. yunnanensis isolate YKG10-61c was used as out group. Number of repetitions used was 1,000 . A $P$ value $>5 \%$ indicates homogeneity in the phylogenetical signal between the fragments used in the partition. After the PTH test, the sequences of six fragments were aligned and combined together into a large fragment using Bioedit software, and used for phylogenetic analysis. The maximum-parsimony (MP) tree was constructed by Mega 5.0 software (Tamura et al. 2011) with the MP method (Thompson et al. 1997), and calculated with the subtree-prunning-regrafting (level =1) and brand-swapping methods, with initial trees generated by random addition (100 reps). Gaps or missing data were treated with a complete deletion option and the reliability of clusters was evaluated by bootstrapping with 1,000 replicates. Meanwhile, the maximum-likelihood (ML) tree was constructed by Mega 5.0 software with the ML method (Guindon and Gascuel 2003) and the Tamura-Nei model was used, with uniform substitution rates. Gaps or missing data were treated with a complete deletion option and the reliability of clusters was evaluated by bootstrapping with 500 replicates.

Fungicides. Four technical-grade fungicides were used in this study: carbendazim (98.1\% active ingredient [a.i.]; Jinbei Chemical Co., Ltd.), tebuconazole ( $96 \%$ a.i.; SheyangHuanghai Pesticides and Chemical Co., Ltd.), azoxystrobin (96\% a.i.; Gengyun Co., Ltd.), and boscalid (97\% a.i.; Kangbaotai Chemical, Co., Ltd.). Each fungicide was dissolved in acetone at a concentration of $1,000 \mu \mathrm{g}$ a.i./ml as stock solutions, except for carbendazim, which was dissolved in $1 \mathrm{M} \mathrm{HCl}$.

In vitro sensitivity assay of $M$. mumecola to carbendazim, tebuconazole, azoxystrobin, and boscalid. After preliminary experiments, the optimum concentrations were decided to perform the in vitro sensitivity test. Carbendazim was used at $0,0.05,0.1$,

Table 2. Primers used to amplify corresponding gene fragments ${ }^{\mathrm{z}}$

\begin{tabular}{|c|c|c|c|}
\hline Primer & Primer sequence & $\begin{array}{l}\text { Primer } \\
\text { length } \\
\text { (bp) }\end{array}$ & $\begin{array}{c}\text { Gene } \\
\text { fragment } \\
\text { amplified }\end{array}$ \\
\hline CYP51F & TACTGGGAAAGAAGACTACG & 20 & $\begin{array}{c}\text { 1,026-bp } \\
\text { CYP51 }\end{array}$ \\
\hline CYP51R & AATATTCTGCATCTCGACTC & 20 & $\begin{array}{r}\text { 1,026-bp } \\
\text { CYP51 }\end{array}$ \\
\hline$T U B 2 \mathrm{~F}$ & ATGCGTGAGATTGTACGTAT & 20 & $\begin{array}{c}\text { 1,630-bp } \\
T U B 2\end{array}$ \\
\hline TUB2R & GTACCAATGCAAGAAAGCCT & 20 & $\begin{array}{c}\text { 1,630-bp } \\
T U B 2\end{array}$ \\
\hline$G 3 P D H F$ & ACGGTCAATTCAAGGGTGAT & 20 & $\begin{array}{l}\text { 786-bp } \\
\text { G3PDH }\end{array}$ \\
\hline$G 3 P D H \mathrm{R}$ & ATCGAAGATGGAGGAGTGGT & 20 & $\begin{array}{l}\text { 786-bp } \\
\text { G3PDH }\end{array}$ \\
\hline$E F-1 \alpha \mathrm{F}$ & TGAGTTCGAGGCTGGTATCT & 20 & $\begin{array}{c}\text { 876-bp } \\
E F-1\end{array}$ \\
\hline$E F-1 \alpha \mathrm{R}$ & GCCTCAACACACATAGGCTT & 20 & $\begin{array}{c}\text { 876-bp } \\
E F-1\end{array}$ \\
\hline Cytb fragment $1 \mathrm{~F}$ & GGTAGATTCCATGCGAGATT & 20 & $\begin{array}{r}\text { 1,011-bp } \\
5^{\prime} C y t b\end{array}$ \\
\hline Cytb fragment $1 \mathrm{R}$ & CATAGGCTCATTTGACCGTA & 20 & $\begin{array}{r}1,011-\mathrm{bp} \\
5^{\prime} \text { Cytb }\end{array}$ \\
\hline Cytb fragment $2 \mathrm{~F}$ & GACAAGCGGAAGGGTATATT & 20 & $\begin{array}{r}\text { 1,046-bp } \\
3^{\prime} C y t b\end{array}$ \\
\hline Cytb fragment $2 \mathrm{R}$ & AGAAGGGAAACGTACTTGTC & 20 & $\begin{array}{r}\text { 1,046-bp } \\
3^{\prime} C y t b\end{array}$ \\
\hline
\end{tabular}

${ }^{\mathrm{z}}$ CYP51 = sterol $14 \alpha$-demethylase gene, $T U B 2=\beta$-tubulin gene, $G 3 P D H=$ glyceraldehydes-3-phosphate dehydrogenase gene, $E F-1 \alpha=$ elongation factor $1 \alpha$ gene, and $C y t b=$ cytochrome b gene. 
0.2 , and $0.4 \mu \mathrm{g} / \mathrm{ml}$; tebuconazole at $0,0.001,0.003,0.01,0.03,0.1$, and $0.3 \mu \mathrm{g} / \mathrm{ml}$; and azoxystrobin and boscalid at $0,0.03,0.1,0.3,1$, 3 , and $10 \mu \mathrm{g} / \mathrm{ml}$. Sensitivities to carbendazim, tebuconazole, and azoxystrobin were assessed on PDA amended with fungicide at concentrations mentioned above. As for QoI fungicide, salicylhydroxamic acid was added at $30 \mu \mathrm{g} / \mathrm{ml}$ to suppress the alternative oxidase pathway. Boscalid was added to minimal medium (10 $\mathrm{g}$ of glucose,
$1.5 \mathrm{~g}$ of $\mathrm{K}_{2} \mathrm{HPO}_{4}, 2 \mathrm{~g}$ of $\mathrm{KH}_{2} \mathrm{PO}_{4}, 1 \mathrm{~g}$ of $\left(\mathrm{NH}_{4}\right) \mathrm{SO}_{4}, 0.5 \mathrm{~g}$ of $\mathrm{MgSO}_{4} \cdot 7 \mathrm{H}_{2} \mathrm{O}, 2 \mathrm{~g}$ of yeast extract, and $12.5 \mathrm{~g}$ of agar per liter) (Hu et al. 2011b). To assay the sensitivity, mycelial plugs were cut with a 6-mm cork borer from the margins of 5-day-old colonies and placed upside down on the centers of 9 -cm plastic petri dishes with media amended with fungicide or not (control). Isolates were incubated at $22^{\circ} \mathrm{C}$ for 5 days in darkness and each isolate was tested in

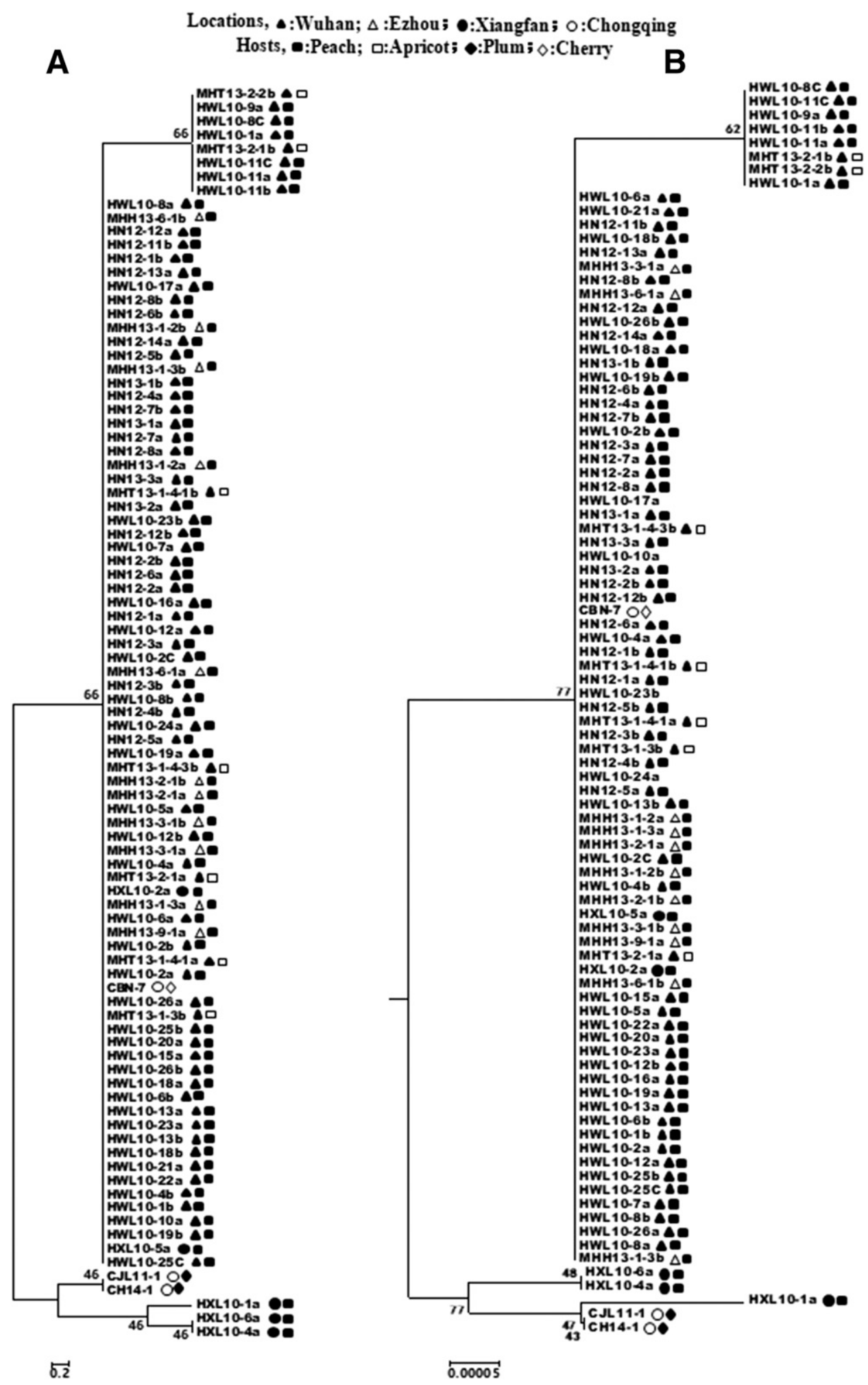

Fig. 1. Phylogenetic trees of 91 Monilia mumecola isolates were constructed by A, maximum-parsimony and B, maximum-likelihood methods. Phylogenetic trees inferred from the data set containing the combined DNA sequences of glyceraldehydes-3-phosphate dehydrogenase, sterol $14 \alpha$-demethylase, $\beta$-tubulin, elongation factor $1 \alpha$, and cytochrome $b$ (fragments 1 and 2) genes. 
triplicate. The effective concentration for 50\% mycelial growth inhibition $\left(\mathrm{EC}_{50}\right)$ value was assessed by regressing percentage of mycelial growth inhibition against the $\log _{10}$ of fungicide concentrations.

Data analysis. The $\mathrm{EC}_{50}$ values were transformed to $\log _{10}$ values and the differences were evaluated by the least significant difference (LSD) test in SPSS software (release 13.0; SPSS Inc.).

\section{Results}

Phylogenetic analysis of M. mumecola isolates. Six fragments of $1,026,1,630,786,876,1,011$, and 1,046 bp were amplified from CYP51, TUB2, G3PDH, EF-1 $\alpha$, Cytb 1, and Cytb 2, respectively, and sequenced. Based on the PTH test, the phylogenetical signal between the fragments used in the partition was homogeneity $(P=$ 0.08 ); thus, these fragments could be combined to perform the phylogenetic analysis. The MP and ML methods revealed two phylogenetic trees with consistent topologies, indicating that the phylogenetic relationship among the tested isolates is statistically reliable (Fig. 1). Phylogenetic analysis revealed that the hosts did not affect the genetic diversity among isolates but the geographical locations showed the obvious influence on the diversity of tested isolates. For example, of the Wuhan isolates, seven isolates from apricot clustered with isolates from peach. And cherry isolate CBN-7 clustered with other isolates from peach, which shows that genetic diversity was low among isolates from different hosts. On the other hand, isolates from different locations tended to fall in the different groups and isolates from far locations showed relatively high genetic variations. For example, Chongqing isolates had the trend to separate from Wuhan and Ezhou isolates, whereas they showed relatively low genetic variations with isolates from Xiangfan, which is nearly located in the middle of Chongqing and Wuhan, Ezhou. Isolates from Wuhan and Ezhou were gathered together because there is only $50 \mathrm{~km}$ between the two locations

Sensitivity of $M$. mumecola isolates to carbendazim, tebuconazole, azoxystrobin, and boscalid. In this study, all 93 tested $M$. mumecola isolates were sensitive to fungicides carbendazim, tebuconazole, azoxystrobin, and boscalid; no resistant isolates were found. The $\mathrm{EC}_{50}$ values of $93 \mathrm{M}$. mumecola isolates to carbendazim ranged from 0.06 to $0.36 \mu \mathrm{g} / \mathrm{ml}$, with a mean value of $0.10 \mu \mathrm{g} / \mathrm{ml}$ (Table 3).

Table 3. Mean effective concentration for $50 \%$ mycelial growth inhibition $\left(\mathrm{EC}_{50}\right)$ values of Monilia mumecola isolates from different regions of China to carbendazim, tebuconazole, azoxystrobin, and boscalid

\begin{tabular}{|c|c|c|c|c|c|c|c|c|c|}
\hline \multirow[b]{3}{*}{ Region } & \multirow[b]{3}{*}{$N^{\mathbf{y}}$} & \multicolumn{8}{|c|}{$\mathrm{EC}_{50}$ to fungicides $(\mu \mathrm{g} / \mathrm{ml})$} \\
\hline & & \multicolumn{2}{|c|}{ Carbendazim } & \multicolumn{2}{|c|}{ Tebuconazole } & \multicolumn{2}{|c|}{ Azoxystrobin } & \multicolumn{2}{|c|}{ Boscalid } \\
\hline & & Range & $\operatorname{Mean}^{z}$ & Range & $\operatorname{Mean}^{z}$ & Range & $\operatorname{Mean}^{\mathrm{z}}$ & Range & $\operatorname{Mean}^{z}$ \\
\hline Chongqing & 3 & $0.09-0.36$ & $0.12 \pm 0.04 \mathrm{a}$ & $0.03-0.13$ & $0.04 \pm 0.02 \mathrm{a}$ & $0.12-0.63$ & $0.21 \pm 0.23 \mathrm{a}$ & $0.23-0.50$ & $0.36 \pm 0.12 \mathrm{a}$ \\
\hline Xiangfan & 5 & $0.07-0.35$ & $0.09 \pm 0.02 \mathrm{a}$ & $0.01-0.04$ & $0.02 \pm 0.01 \mathrm{a}$ & $0.15-0.54$ & $0.36 \pm 0.17 \mathrm{a}$ & $0.19-1.55$ & $0.66 \pm 0.53 \mathrm{a}$ \\
\hline Ezhou & 11 & $0.06-0.13$ & $0.09 \pm 0.02 \mathrm{a}$ & $0.01-0.10$ & $0.04 \pm 0.03 \mathrm{a}$ & $0.01-0.10$ & $0.04 \pm 0.09 \mathrm{a}$ & $0.07-1.72$ & $0.53 \pm 0.62 \mathrm{a}$ \\
\hline Wuhan & 74 & $0.07-0.27$ & $0.10 \pm 0.04 \mathrm{a}$ & $0.01-0.11$ & $0.03 \pm 0.02 \mathrm{a}$ & $0.05-1.25$ & $0.33 \pm 0.18 \mathrm{a}$ & $0.01-1.70$ & $0.33 \pm 0.48 \mathrm{a}$ \\
\hline Total & 93 & $0.06-0.36$ & $0.10 \pm 0.04$ & $0.01-0.13$ & $0.03 \pm 0.02$ & $0.01-1.25$ & $0.33 \pm 0.22$ & $0.01-1.72$ & $0.42 \pm 0.48$ \\
\hline
\end{tabular}

y Number of isolates.

${ }^{\mathrm{z}}$ Mean \pm standard deviation; values within the same column followed by the same letters are not significantly different with the least significant difference test at $P=0.05$.

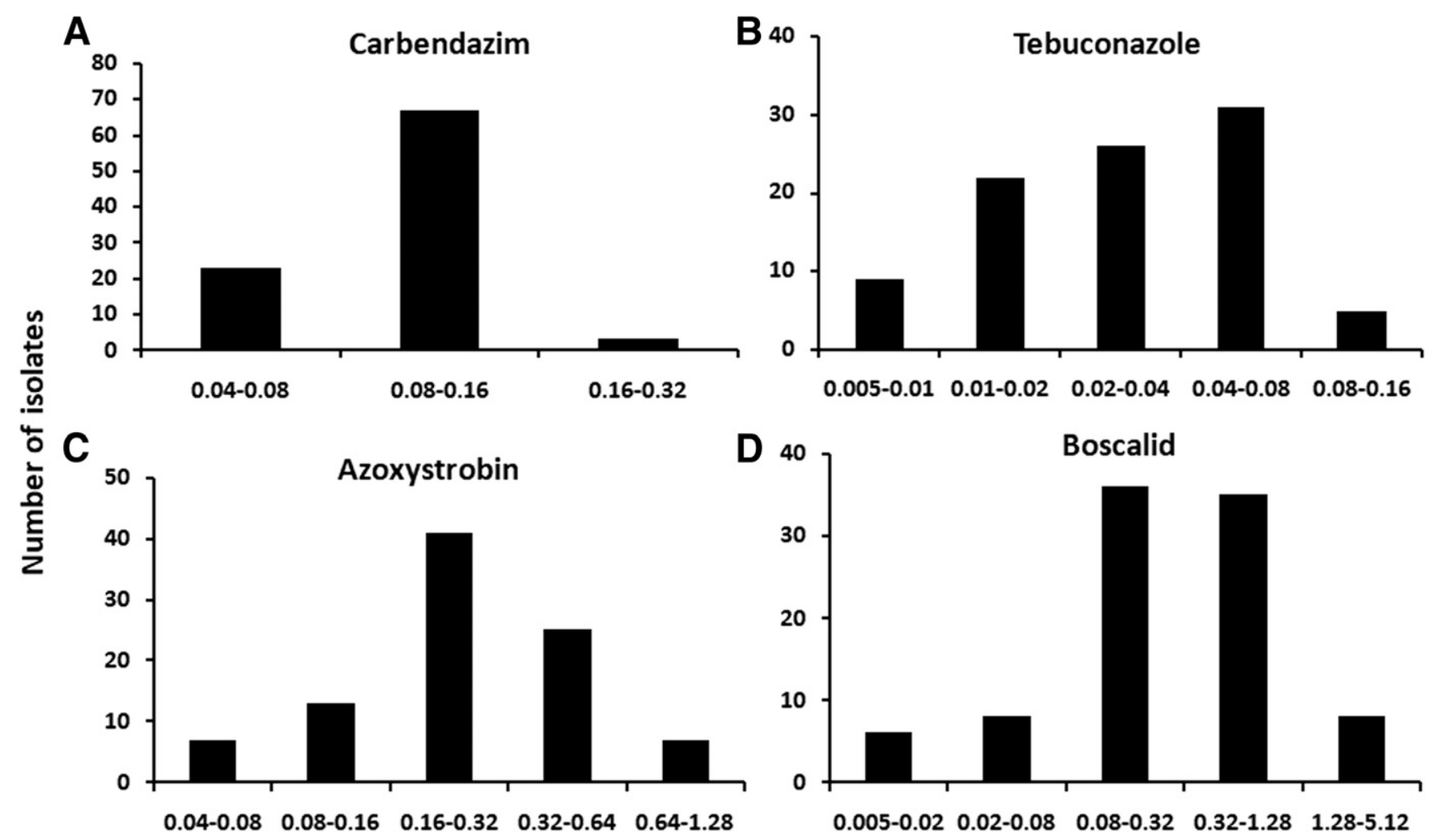

Fig. 2. Distribution of effective concentration for $50 \%$ mycelial growth inhibition $\left(\mathrm{EC}_{50}\right)$ values in Monilia mumecola isolates for four fungicides $\mathbf{A}$, carbendazim; $\mathbf{B}$, tebuconazole; C, azoxystrobin; and D, boscalid. 
The $\mathrm{EC}_{50}$ values show the near-normal distribution and the highest $\mathrm{EC}_{50}$ value was 6 times the lowest one (Fig. 2A; Table 3). The $\mathrm{EC}_{50}$ values for tebuconazole showed a continuous single peak curve (Fig. 2B), and ranged from 0.01 to $0.13 \mu \mathrm{g} / \mathrm{ml}$, with a mean value of $0.03 \mu \mathrm{g} / \mathrm{ml}$ (Table 3). The highest to the lowest $\mathrm{EC}_{50}$ value was 13 . The $\mathrm{EC}_{50}$ value for azoxystrobin was unimodal (Fig. 2C), ranged from 0.01 to $1.25 \mu \mathrm{g} / \mathrm{ml}$ with a mean of $0.33 \mu \mathrm{g} / \mathrm{ml}$, and the highest $\mathrm{EC}_{50}$ value to the lowest was 125 (Table 3). The sensitivity of 93 isolates to boscalid also distributed as a continuous single peak curve (Fig. 2D) and the span of their $\mathrm{EC}_{50}$ values was 0.01 to 1.72 , with a mean of $0.42 \mu \mathrm{g} / \mathrm{ml}$. The highest $\mathrm{EC}_{50}$ value was 172 times that of the lowest one (Table 3 ).

Fungicide sensitivity of isolates from different regions. LSD variance analysis of sensitivity to four fungicides among isolates from Chongqing, Xiangfan, Ezhou, and Wuhan showed that there were no significant differences among isolates from different regions (Table 3). The $\mathrm{EC}_{50}$ values of isolates from Wuhan to boscalid ranged from 0.01 to 1.70 (Table 3 ), wider than isolates from other regions, most likely because more isolates were collected from Wuhan.

\section{Discussion}

M. mumecola was first reported as a new species in Japan as the causal agent of mume brown rot disease in 2004 (Harada et al. 2004). Studies in China showed that it can cause brown rot disease on peach, plum, apricot, cherry (Hu et al. 2011a; Yin et al. 2014a,b, 2015, 2017), and Chinese quince (Shao 2009). In spite of its wide host spectrum, it has a narrow geographical distribution worldwide and, thus far, has only been reported in China and Japan. Exhaustive sampling in China included 11 provinces or municipalities but M. mumecola was only detected in Hubei Province and Chongqing municipality (Hu et al. 2011a; Yin et al. 2014a,b, 2015, 2017). However, Hubei Province is one of the four leading peach producers in China; therefore, M. mumecola has a considerable influence on Chinese peach industry.

A previous study showed that the Monilia spp. isolates clustered according to species rather than geographical location or host origin (Yin et al. 2015). This study suggests that geographical location played a more important role than host within species. For instance, the isolates from Wuhan and Ezhou clustered primarily together and the distance between the orchards was less than $50 \mathrm{~km}$. As expected, most of the isolates from Wuhan and Ezhou did not cluster with isolates from Xiangfan and Chongqing, which are separated by more than $300 \mathrm{~km}$. However, the Wuhan isolates from apricot completely gathered together with the isolates from peach and nectarine, showing the low genetic variations among the isolates from three hosts. These results show that the host has less influence on M. mumecola during the evolutionary process compared with the geographical location, suggesting that the $M$. mumecola isolates may infect different hosts in the same places. The inadequacy of the current study is that only three $M$. mumecola isolates were obtained from Chongqing whereas hundreds of Monilia isolates were isolated during 2010 to 2013, most of which were $M$. fructicola isolates.

Up to now, fungicide application was still an effective strategy to control peach brown rot disease. Highly efficacious, site-specific fungicides such as MBCs, DMIs, QoIs, and SDHIs were always the priority for commercial peach producers. For the three Monilia spp., M. fructicola has been extensively studied for its resistance to four common fungicides (MBCs, DMIs, QoIs, and SDHIs) and resistance to carbendazim has been detected in Beijing, Shandong Province (Fan et al. 2009), and Yunnan Province (Chen et al. 2014). The sensitive $M$. fructicola isolates showed $\mathrm{EC}_{50}$ values of 0.003 to $1.21 \mu \mathrm{g} / \mathrm{ml}$ with a mean value of $0.13 \mu \mathrm{g} / \mathrm{ml}$ (Chen et al. 2014), indicating the similar sensitivity to carbendazim but wider ranges compared with $M$. mumecola ( 0.06 to 0.36 , with a mean of $0.10 \mu \mathrm{g} / \mathrm{ml}$ ). Sensitive $M$. fructicola isolates showed $\mathrm{EC}_{50}$ values of 0.01 to $0.15 \mu \mathrm{g} / \mathrm{ml}$ for tebuconazole, with a mean value of $0.03 \mu \mathrm{g} / \mathrm{ml}$ (Chen et al. 2014), indicating sensitivity similar to M. mumecola (0.01 to 0.13 , with a mean of $0.03 \mu \mathrm{g} / \mathrm{ml}$ ). For azoxystrobin, the sensitive $M$. fructicola isolates showed $\mathrm{EC}_{50}$ values of 0.02 to $1.94 \mu \mathrm{g} / \mathrm{ml}$, with a mean value of $0.54 \mu \mathrm{g} / \mathrm{ml}$ (Chen et al. 2014), very similar to $M$. mumecola ( 0.01 to 1.25 , with a mean of $0.33 \mu \mathrm{g} / \mathrm{ml}$ ). The sensitive $M$. fructicola isolates showed $\mathrm{EC}_{50}$ values of 0.14 to 2.88 $\mu \mathrm{g} / \mathrm{ml}$ for boscalid, with a mean value of $1.02 \mu \mathrm{g} / \mathrm{ml}$ (Chen et al. 2014), indicating a little reduced sensitivity compared with $M$. mumecola (0.01 to 1.72 , with a mean of $0.42 \mu \mathrm{g} / \mathrm{ml})$. M. yunnanensis has also been evaluated for sensitivity to two DMI fungicides (tebuconazole and triadimefon), and no resistance was found (Yuan et al. 2013). The sensitive $M$. yunnanensis isolates showed $\mathrm{EC}_{50}$ values of 0.0001 to $0.06 \mu \mathrm{g} / \mathrm{ml}$, with a mean value of $0.01 \mu \mathrm{g} / \mathrm{ml}$, for tebuconazole (Yuan et al. 2013), indicating similar sensitivity but wider ranges compared with $M$. mumecola ( 0.01 to 0.13 , with a mean of $0.03 \mu \mathrm{g} / \mathrm{ml}$ ). To date, no report could be found for sensitivity to fungicides in M. mumecola. The current study is the first to convey fungicide sensitivity in $M$. mumecola populations and results showed that no resistance occurred to four groups of fungicides (MBCs, DMIs, QoIs, and SDHIs), indicating that these four chemical classes of fungicides still can be used to control brown rot caused by $M$. mumecola in China. It should be noted that, although some isolates were from several small orchards with a history of occasional carbendazim application, these isolates are still very sensitive to carbendazim in this study; thus, we think those isolates are still proper as a baseline population.

In conclusion, genetic diversity analysis revealed that, within the $M$. mumecola species, the geographical environment played a more important role than host during the evolution of M. mumecola. Attention should be paid when brown rot occurs on a certain host, because it may attack other hosts in the same areas. The sensitivity of $M$. mumecola was assayed to four fungicides from different classes. No field resistance was detected and the baseline sensitivities were established for four classes of fungicides-MBC, DMI, QoI, and SDHI-in M. mumecola in China. Because resistance has occurred in M. fructicola in China, the monitoring of the development of resistance should also be carried out in M. mumecola populations.

\section{Literature Cited}

Amiri, A., Brannen, P., and Schnabel, G. 2010. Reduced sensitivity in Monilinia fructicola field isolates from South Carolina and Georgia to respiration inhibitor fungicides. Plant Dis. 94:737-743.

Burnett, A., Lalancette, N., and McFarland, K. 2010. First report of the peach brown rot fungus Monilinia fructicola resistant to demethylation inhibitor fungicides in New Jersey. Plant Dis. 94:126.

Chen, F., Liu, X., Chen, S., Schnabel, E., and Schnabel, G. 2013a. Characterization of Monilinia fructicola isolates resistant to both propiconazole and boscalid. Plant Dis. 97:645-651.

Chen, F., Liu, X., and Schnabel, G. 2013b. Field isolates of Monilinia fructicola resistant to both MBC and DMI fungicides isolated from stone fruit orchards in the eastern United States. Plant Dis. 97:1063-1068.

Chen, S. N., Shang, Y., Wang, Y., Schnabel, G., Lin, Y., Yin, L. F., and Luo, C. X. 2014. Sensitivity of Monilinia fructicola from peach farms in China to four fungicides and characterization of isolates resistant to carbendazim and azoxystrobin. Plant Dis. 98:1555-1560.

Egüen, B., Melgarejo, P., and De Cal, A. 2016. The effect of fungicide resistance on the structure of Monilinia laxa populations in Spanish peach and nectarine orchards. Eur. J. Plant Pathol. 145:815-827.

Elmer, P. A. G., Braithwaite, M., and Braithwaite, D. J. 1992. Changes in triforine sensitivity in populations of Monilinia fructicola from Hawkes Bay orchards. Pages 138-140 in: Proc. 45th N. Z. Plant Prot. Conf.

Fan, J., Fang, Y., and Guo, L. 2009. Sensitivity of Monilinia fructicola isolates to thiophanate-methyl and boscalid. Acta Phytophylac. Sin. 36:251-256.

Fang, Y. L., Liu, P., and Guo, L.-Y. 2010. Sensitivity of Monilinia fructicola isolates to azoxystrobin. J. Fruit Sci. 27:561-565

Guindon, S., and Gascuel, O. 2003. A simple, fast, and accurate algorithm to estimate large phylogenies by maximum likelihood. Syst. Biol. 52:696-704.

Harada, Y., Nakao, S., Sasaki, M., Sasaki, Y., Ichihashi, Y., and Sano, T. 2004 Monilia mumecola, a new brown rot fungus on Prunus mume in Japan. J. Gen. Plant Pathol. 70:297-307.

Harada, Y., Sasaki, M., and Nakao, S. 1990. On occurrence in recent years of brown rot disease on Prunus mume in Oita Pref. and its causal fungus. Ann. Phytopathol. Soc. Jpn. 59:387.

Hu, M. J., Cox, K. D., Schnabel, G., and Luo, C.-X. 2011a. Monilinia species causing brown rot of peach in China. PLoS One 6:e24990.

Hu, M. J., Luo, C. X., Grabke, A., and Schnabel, G. 2011b. Selection of a suitable medium to determine sensitivity of Monilinia fructicola mycelium to SDHI fungicides. J. Phytopathol. 159:616-620.

Luo, C. X. 2017. Advances and prospects on researches of brown rot disease on fruits. Acta Phytopathol. Sin. 47:145-153 (in Chinese). 
Luo, C. X., Cox, K. D., Amiri, A., and Schnabel, G. 2008. Occurrence and detection of the DMI resistance-associated genetic element 'Mona' in Monilinia fructicola. Plant Dis. 92:1099-1103.

Ma, Z., Yoshimura, M. A., Holtz, B. A., and Michailides, T. J. 2005. Characterization and PCR-based detection of benzimidazole-resistant isolates of Monilinia laxa in California. Pest Manage. Sci. 61:449-457.

Ma, Z., Yoshimura, M. A., and Michailides, T. J. 2003. Identification and characterization of benzimidazole resistance in Monilinia fructicola from stone fruit orchards in California. Appl. Environ. Microbiol. 69:7145-7152.

Malandrakis, A., Markoglou, A. N., and Ziogas, B. N. 2012. PCR-RFLP detection of the E198A mutation conferring resistance to benzimidazoles in field isolates of Monilinia laxa from Greece. Crop Prot. 39:11-17.

Malandrakis, A., Nikolaos, K., Veloukas, T., Karaoglanidis, G., and Markoglou, A. 2013. Baseline sensitivity of Monilinia laxa from Greece to fenhexamid and analysis of fenhexamid-resistant mutants. Crop Prot. 46:13-17.

May-De Mio, L. L., Luo, Y., and Michailides, T. J. 2011. Sensitivity of Monilinia fructicola from Brazil to tebuconazole, azoxystrobin, and thiophanate-methyl and implications for disease management. Plant Dis. 95:821-827.

Michailides, T., Ogawa, J., and Opgenorth, D. 1987. Shift of Monilinia spp. and distribution of isolates sensitive and resistant to benomyl in California prune and apricot orchards. Plant Dis. 71:893-896.

Schnabel, G., Bryson, P. K., Bridges, W. C., and Brannen, P. M. 2004. Reduced sensitivity in Monilinia fructicola to propiconazole in Georgia and implications for disease management. Plant Dis. 88:1000-1004.

Shao, W. 2009. Etiology, Occurrence and Control of Papaya (Chaenomeles lagenaria) Brown Rot. Huazhong Agricultural University, Wuhan, China.

Spiegel, J., and Stammler, G. 2006. Baseline sensitivity of Monilinia laxa and M. fructigena to pyraclostrobin and boscalid. J. Plant Dis. Prot. 113:199-206.

Swofford, D. L. 2003. PAUP* Phylogenetic Analysis Using Parsimony, (*and Other Methods), Version 4.0 b10. Sinauer Associates, Sunderland, MA, U.S.A.
Szkolnik, M., and Gilpatrick, J. D. 1977. Tolerance of Monilinia fructicola to benomyl in western New York State orchards. Plant Dis. Rep. 61:654-657.

Tamura, K., Peterson, D., Peterson, N., Stecher, G., Nei, M., and Kumar, S. 2011 MEGA5: Molecular evolutionary genetics analysis using maximum likelihood, evolutionary distance, and maximum parsimony methods. Mol. Biol. Evol. 28: 2731-2739.

Thomidis, T., Michailides, T., and Exadaktylou, E. 2009. Contribution of pathogens to peach fruit rot in Northern Greece and their sensitivity to iprodione, carbendazim, thiophanate-methyl and tebuconazole fungicides. J. Phytopathol. 157:194-200.

Thompson, J., Gibson, T., Plewniak, F., Jeanmougin, F., and Higgins, D. 1997. The CLUSTAL_X windows interface: Flexible strategies for multiple sequence alignment aided by quality analysis tools. Nucleic Acids Res. 25: 4876-4882.

Villani, S., and Cox, K. 2008. QoI sensitivity and the prevalence of DMI resistance in NY populations of the brown rot pathogen Monilinia fructicola. (Abstr.) Phytopathology 98:S163.

Yin, L. F., Cai, M. L., Du, S. F., and Luo, C. X. 2017. Identification of two Monilia species from apricot in China. J. Integr. Agric. 16:2496-2503.

Yin, L. F., Chen, G. K., Chen, S. N., Du, S. F., Li, G. Q., and Luo, C. X. 2014a First report of brown rot caused by Monilia mumecola on Chinese sour cherry in Chongqing municipality, China. Plant Dis. 98:1009.

Yin, L. F., Chen, S. N., Cai, M. L., Li, G. Q., and Luo, C. X. 2014b. First report of brown rot of apricot caused by Monilia mumecola. Plant Dis. 98:694.

Yin, L. F., Chen, S. N., Chen, G. K., Schnabel, G., Du, S. F., Chen, C., Li, G. Q. and Luo, C. X. 2015. Identification and characterization of three Monilinia species from plum in China. Plant Dis. 99:1775-1783.

Yuan, N. N., Chen, S. N., Zhai, L. X., Schnabel, G., Yin, L. F., and Luo, C. X. 2013. Baseline sensitivity of Monilia yunnanensis to the DMI fungicides tebuconazole and triadimefon. Eur. J. Plant Pathol. 136:651-655. 